\title{
Studi Populasi Owa Jawa (Hylobates moloch) di Lereng Gunung Slamet Jawa Tengah
}

\author{
Sri Wahyuni ${ }^{1)}$, Erie Kolya Nasution ${ }^{1)}$ \\ ${ }^{1}$ Fakultas Biologi, Universitas Jenderal Soedirman \\ Jalan dr. Suparno 63 Purwokerto 53122`email: erikolya284@gmail.com
}

\begin{abstract}
Javanese Gibbon (Hylobates moloch) is the endemic primate species in Indonesia. IUCN - World Concervation has given this species an endangered status. The habitat Hylobates moloch's were found at Mount Slamet in Central Java. The study aimed to determine of population in Mount Slamet. This research was conducted in the exact line during July-November 2014, with stratified sampling base on line transect. Transects pathway in this study used existing pathways wich the passed and cut the contour of research sites. Javanese Gibbon (Hylobates moloch) obtained along the transect was calculated and analyzed using perpendiculars distance approach (DISTANCE 5.0's software). Analysis by DISTANCE 5.0 showed that the density of Javanese Gibbon (Hylobates moloch) at Slamet Mountain in $170 \mathrm{~km}^{2}$ area was 0.26 individual $/ \mathrm{km}^{2}$, coefficient of variation was $34.88 \%$, lower limit of $95 \%$ confidence interval was 0.13 to 0.52 . Based on the analysis, total number of javanese gibbon population at Mount Slamet was 45 individuals of the density 0.26 individuals.
\end{abstract}

Keywords : Javanese Gibbon (Hylobates moloch), population, slopes of Mount Slamet

\begin{abstract}
Abstrak
Owa jawa (Hylobates moloch) merupakan salah satu spesies primata endemik di Indonesia. IUCN-World Concervation memberikan status terancam punah (Endangered). Salah satu habitat owa jawa terdapat di Gunung Slamet Jawa Tengah. Penelitian bertujuan untuk mengetahui jumlah populasi di Lereng Gunung Slamet. Penelitian dilaksanakan Juli-Nopember 2014 dengan teknik stratified random sampling.dan line transsect Jalur transek untuk lokasi penelitian dengan memanfaatkan jalur yang sudah ada, tetapi di pilih jalur yang melewati dan memotong kontur lokasi penelitian. Owa jawa yang diperoleh sepanjang garis transek dihitung dan dianalisis menggunakan pendekatan perpendiculars distance dalam program komputer DISTANCE 5.0. Hasil analisis menunjukkan bahwa kepadatan owa jawa di Gunung Slamet yang memiliki luas areal $170 \mathrm{~km}^{2}$ adalah 0.26 individu $/ \mathrm{km}^{2}$ dengan selang kepercayaan $95 \%$, kisaran kepadatannya $0.13-0.52$. Berdasarkan hasil analisis diperoleh estimasi populasi owa jawa di kawasan Gunung Slamet adalah 45 individu dengan kepadatan 0,26 individu
\end{abstract}

Kata kunci : Owa jawa (Hylobates moloch), populasi, Lereng Gunung Slamet

\section{Pendahuluan}

Owa jawa (Hylobates moloch) merupakan satu dari enam spesies genus Hylobates yang hidup di Indonesia (Setyawan et al., 2012; Meijaard \& Nijman, 2000) Spesies ini merupakan spesies endemik dan hanya terdapat di Pulau Jawa yaitu di wilayah Provinsi Jawa Barat dan Jawa Tengah tepatnya di daerah hutan hujan tropis, mulai dari dataran rendah, pesisir, hingga pegunungan pada ketinggian $1.400-1.600 \mathrm{~m}$ dpl. Persebarannya meliputi wilayah Jawa Barat di antaranya yaitu, Taman Nasional (TN) Ujung Kulon, TN Gunung Gede Pangrango, TN Gunung Halimun, Cagar Alam (CA) Gunung Siampang, CA Leuwang Sancang, dan Jawa Tengah seperti Gunung Slamet hingga pegunungan Dieng (Supriatna dan Wahyono, 2000; Chivers, 1974).

Habitat alami owa jawa yang merupakan hutan primer telah banyak dikonversi menjadi lahan pertanian dan pemukiman penduduk. Habitat owa jawa di Gunung Simpang mengalami pengurangan sebesar $15 \%$ dari
15.000 ha, Taman Nasional Ujung Kulon sebesar 4\% dari 76.100 dan Taman Nasional Gunung Halimun sebesar 2,5\% dari 42.000 ha (Supriatna, 2006). Nijman (2004) melaporkan sebagian besar habitat alami owa jawa telah berkurang, di Jawa Tengah dan Jawa Barat habitat owa jawa hanya tertinggal 10\% dari keseluruhan hutan alam yang ada, yang terdiri dari $59 \%$ hutan pegunungan, $10 \%$ dari keseluruhan hutan dataran tinggi dan $2 \%$ hutan dataran rendah. Beberapa bagian hutan yang penting bagi perlindungan populasi owa jawa dinilai tidak mempunyai status konservasi yang jelas.

Fragmentasi hutan, perdagangan liar dan hewan peliharaan merupakan ancaman paling serius bagi kelestarian owa jawa (Supriatna, 2006). Selanjutnya Supriatna et al., (2001) mengatakan gangguan terhadap habitat seperti aktivitas penebangan, merupakan ancaman bagi kelestarian populasi owa jawa karena mengakibatkan hilang serta menyempitnya habitat serta menciptakan kepunahan spesies. Menurut IUCN-World Concervation owa jawa 
termasuk spesies primata dengan kategori terancam (endangered) (IUCN/SSC, 2009). Tahun 2000 owa jawa masuk ke dalam daftar 25 jenis primata yang paling rentan terhadap kepunahan (Supriatna et al., 2001; Whitmore, 1984).

Owa jawa telah dinyatakan sebagai fauna yang dilindungi berdasar Perlindungan Binatang Liar tahun 1931 Nomor 266, SK Menteri Kehutanan No.54/Kpt/Um/1972 dan Peraturan Pemerintah No.7 Tahun 1990 (Kartono et al., 2002). Penyusutan habitat dan tekanan perburuan menyebabkan populasi spesies kera kecil ini terus mengalami penurunan dan semakin terdesak sebarannya hanya pada kawasan hutan yang dilindungi.Penurunan populasi di alam tersebut sangat memprihatinkan, hal ini berkaitan dengan semakin langkanya owa jawa di alam.

Program pelestarian owa jawa melalui konservasi exsitu diharapkan tidak hanya menjadi sarana penangkaran bagi spesies tersebut namun diharapkan mampu menunjang konservasi insitu melalui program pelepasliaran ke habitat alami. Pusat Studi Satwa Primata (PSSP) merupakan salah satu instansi yang bergerak dalam pengembangan riset terkait primata yang tidak hanya terfokus pada aspek biomedis, biologi namun juga pada aspek pelestarian spesies primata.Program penangkaran exsitu yang dilakukan oleh PSSP merupakan upaya dalam mendukung pelestarian satwa primata, terutama bagi spesies yang terancam punah seperti penangkaran owa jawa dan beberapa satwa primata lainnya.

Menurut Djanubudiman et al. (2004) di lereng Gunung Slamet hanya tersisa 96 ekor. Gunung Slamet dengan ketinggian (3428 m dpl) terdapat di titik koordinat $7^{\circ} 15^{\prime} 33$ LS $109^{\circ} 13^{\prime} 05$ BT merupakan salah satu habitat penting owa jawa. Hingga saat ini populasi owa jawa terbesar di Pulau Jawa belum diketahui dengan baik. Hutan Lindung Gunung Slamet diperkirakan dapat menunjang populasi owa jawa yang cukup besar. Nijman (2001) memperkirakan populasi owa jawa di Gunung Slamet mencapai 100 individu. Hal ini didasarkan perkiraan luas hutan di bawah ketinggian $1.500 \mathrm{~m}$ dpl seluas $40 \mathrm{~km}^{2}$ dengan kondisi yang cukup baik.

Berdasarkan uraian di atas didapat permasalahan yaitu barapakah populasi owa jawa yang ada di Lereng Gunung Slamet Jawa Tengah. Adanya permasalahan tersebut perlu dilakukan penelitian dengan tujuan untuk mengetahui populasi owa jawa di lereng Gunung Slamet Jawa Tengah.

Hasil penelitian ini diharapkan dapat memberi informasi mengenai populasi owa jawa yang berada di lereng Gunung Slamet yang kemudian dapat digunakan sebagai pertimbangan dalam upaya peningkatan perlindungan dan pelestarian owa jawa.

\section{Metode Penelitian}

Gunung Slamet merupakan gunung tertinggi di Jawa Tengah yang merupakan salah satu gunung berapi yang masih aktif dipulau Jawa dengan ketinggian $3428 \mathrm{~m}$ dpl, terbagi dalam 4 sisi yaitu lereng selatan, lereng utara, lereng timur dan lereng barat.

Lokasi pengambilan data populasi owa jawa dilakukan di kawasan hutan lindung Gunung Slamet yang pengelolaannya dibawah otoritas Perum Perhutani Unit I Jawa Tengah yaitu Lereng Selatan di daerah Kalipagu, Semaya dan Cipendok, Lereng Barat di daerah Kaligua, Lereng Timur di daerah Bambangan dan Gunung Malang.

Metode yang digunakan adalah metode survey dengan teknik sampling stratified (random) sampling dengan line transect method (Buckland et al., 1993). Jalur transek untuk lokasi penelitian dengan memanfaatkan jalur yang sudah ada, tetapi di pilih jalur yang melewati dan memotong kontur lokasi penelitian.

Jumlah transek seluruhnya ada 20 transek, jarak masing-masing transek $100 \mathrm{~m}$. Panjang total ke 20 transek pada enam lokasi adalah 12 kilometer. Perhitungan populasi dilakukan dengan menghitung jumlah masing-masing kelompok owa jawa yang ditemukan sepanjang garis transek. Setiap transek diamati selama 3 hari dan dilakukan 2 kali ulangan dengan selang waktu satu bulan. Kelas umur owa yang dijumpai diklasifikasikan ke dalam: dewasa (Adult), remaja (Sub Adult), anak-anak (Juvenile), bayi (Infant).

Jenis tumbuhan sebagai pohon pakan dan pohon tidur diamati sepanjang garis transek Data populasi owa jawa yang dianalisis menggunakan pendekatan perpendiculars distance dengan software DISTANCE 5.0.

\section{Hasil dan Pembahasan}

\section{Populasi owa jawa}

Pengamatan populasi owa jawa di peroleh 45 individu dengan kepadatan 0,26 individu/ $\mathrm{km}^{2}$ pada beberapa lokasi di lereng selatan Gunung Slamet yang terletak diketinggian 800 sampai $1400 \mathrm{~m}$ dpl (tabel.1).

Hasil pengamatan di lokasi Kalipagu lereng selatan Gunung Slamet telah diperoleh 6 kelompok owa jawa. Kelompok yang paling banyak adalah pada transek 1_7 yaitu terdapat 3 kelompok dengan jarak masing-masing kelompok kurang dari 500 meter, sehingga kepadatan owa jawa di daerah Kalipagu lebih 
tinggi daripada lokasi penelitian lain. Rendahnya kepadatan dan ukuran kelompok owa jawa di lokasi penelitian dapat disebabkan berbagai faktor antara lain kualitas habitat yang semakin menurun dan besar-kecilnya gangguan, perburuan dan konversi habitat.Menurut Alikodra (2002) mengatakan habitat dengan kualitas yang tinggi akan menghasilkan kehidupan satwa yang lebih
baik.Sebaliknya habitat yang rendah kualitasnya akan menghasilkan kondisi populasi satwa dengan daya reproduksi rendah. Habitat yang sesuai bagi owa jawa adalah hutan dengan tajuk relatif tertutup,tajuk pohon yang memiliki percabangan horizontal,pohon yang mempunyai sumber pakan yang tersedia sepanjang tahun (Kappeler,1984)

Tabel1. Hasil pengamatan populasi owa jawa di Kalipagu

\begin{tabular}{|c|c|c|c|c|c|c|c|c|c|}
\hline Desa & Transek & Koordinat & Elv & $\begin{array}{l}\text { jumlah } \\
\text { individu } \\
\text { terlihat }\end{array}$ & $\begin{array}{l}\text { arah } \\
\text { transek }\end{array}$ & $\begin{array}{c}\text { arah } \\
\text { individu }\end{array}$ & Jarak & PPD & $\begin{array}{l}\text { Habitat/ } \\
\text { Lokasi }\end{array}$ \\
\hline \multirow{6}{*}{ Kalipagu } & $1 \_7$ & $\begin{array}{l}301.544,008 \mathrm{~S} \\
9.191 .469,524 \mathrm{E}\end{array}$ & 750 & 4 & utara & 330 & 100 & -1.323 .816 .292 & $\begin{array}{l}\text { hutan } \\
\text { heterogen }\end{array}$ \\
\hline & $1 \_7$ & $\begin{array}{l}301.543,479 \mathrm{~S} \\
9,192.235,759 \mathrm{E}\end{array}$ & 750 & 3 & utara & 340 & 110 & 7.153.418.142 & $\begin{array}{l}\text { hutan } \\
\text { heterogen }\end{array}$ \\
\hline & $1 \_7$ & $\begin{array}{l}301.547,448 \\
9.192 .382,471 \mathrm{E}\end{array}$ & 800 & 3 & utara & 340 & 105 & 6.828.262.772 & $\begin{array}{l}\text { hutan } \\
\text { heterogen }\end{array}$ \\
\hline & $1 \_8$ & $\begin{array}{l}301.649,683 ; \\
9.192 .338,903 \mathrm{E}\end{array}$ & 700 & 2 & selatan & 330 & 77 & -1.019 .338 .545 & $\begin{array}{l}\text { hutan } \\
\text { heterogen }\end{array}$ \\
\hline & 1_9 & $\begin{array}{l}301.748,507 ; \\
9.192 .065,924 \mathrm{E}\end{array}$ & 700 & 2 & utara & 45 & 130 & 1.106.174.582 & $\begin{array}{l}\text { hutan } \\
\text { heterogen }\end{array}$ \\
\hline & 1_22 & $\begin{array}{l}303.047,614 ; \\
9.192 .057,986 \mathrm{E}\end{array}$ & 680 & 2 & selatan & 345 & 115 & -62.559 .519 & $\begin{array}{l}\text { hutan } \\
\text { heterogen }\end{array}$ \\
\hline \multirow{2}{*}{ Semaya } & 2_15 & $\begin{array}{l}299.211,942 \\
9.190 .532,660 \mathrm{E}\end{array}$ & 600 & 4 & utara & 340 & 90 & 5.852 .796 .661 & $\begin{array}{l}\text { Hutan } \\
\text { heterogen }\end{array}$ \\
\hline & 2_18 & $\begin{array}{l}299.518,330 ; \\
9.191 .684,394 \mathrm{E}\end{array}$ & 750 & 3 & selatan & 300 & 60 & -5.998 .535 .039 & $\begin{array}{l}\text { Hutan } \\
\text { heterogen }\end{array}$ \\
\hline \multirow{2}{*}{ Cipendok } & 3_10 & $\begin{array}{l}294.248,742 \mathrm{~S} \text {; } \\
9.188 .950,941 \mathrm{E}\end{array}$ & 700 & 2 & selatan & 330 & 100 & -1.323 .816 .292 & $\begin{array}{l}\text { Hutan } \\
\text { heterogen }\end{array}$ \\
\hline & 3_14 & $\begin{array}{l}294.648,925 \text { LS ; } \\
9.189 .089,848 \mathrm{E}\end{array}$ & 750 & 3 & selatan & 200 & 150 & -1.309 .945 .946 & $\begin{array}{l}\text { Hutan } \\
\text { heterogen }\end{array}$ \\
\hline Kaligua & 4_4 & $\begin{array}{l}\text { 298.635,678 LS; } \\
9.197 .374,270 \mathrm{E}\end{array}$ & 1700 & 4 & Timur & 330 & 75 & -992.862 .219 & $\begin{array}{l}\text { Hutan } \\
\text { heterogen }\end{array}$ \\
\hline \multirow{2}{*}{ Bambangan } & $5 \_8$ & $\begin{array}{l}306.352,356 \mathrm{~S} ; \\
9.199 .305,810 \mathrm{E}\end{array}$ & 1700 & 2 & Timur & 300 & 50 & -49.987 .792 & $\begin{array}{l}\text { Hutan } \\
\text { heterogen }\end{array}$ \\
\hline & 5_21 & $\begin{array}{l}306.996,226 \mathrm{~S} ; \\
9.200 .598,038 \mathrm{E}\end{array}$ & 1900 & 7 & Barat & 320 & 20 & -8.563 .108 .562 & $\begin{array}{l}\text { Hutan } \\
\text { heterogen }\end{array}$ \\
\hline $\begin{array}{l}\text { Gunung } \\
\text { Malang }\end{array}$ & $6 \_5$ & $\begin{array}{l}306.705,618 \mathrm{~S} ; \\
9.195 .341,374 \mathrm{E}\end{array}$ & 1500 & 3 & utara & 270 & 88 & -1.549 .204 .329 & $\begin{array}{l}\text { Hutan } \\
\text { heterogen }\end{array}$ \\
\hline
\end{tabular}

Keterangan :

Transek 1_7 : lokasi 1 (kalipagu) dan nomor transek 7

Elv : jarak peneliti dgn hewan

PPD : garis tegak lurus peneliti ke hewan

Hasil pengamatan di lokasi Kalipagu lereng Jumlah populasi owa jawa yang ditemukan antara lain anakan owa jawa berjumlah 6 individu anakan, remaja 27 individu dan dewasa 12 individu (gambar 2). Owa jawa di Gunung Slamet yang paling banyak ditemukan dari kelompok remaja. Nijman (2001) memperkirakan ukuran populasi owa jawa di Gunung Slamet 100 individu dengan asumsi hutan di bawah ketinggian $1500 \mathrm{~m}$ dpl luasnya $40 \mathrm{~km}^{2}$ terdapat 61 individu dewasa. Menurut penelitian Widiyanto (2001) perhitungan luas hutan lereng Gunung Slamet ukuran populasi owa jawa diperkirakan 156 individu. Berdasarkan hasil penelitian ini, populasi owa jawa di Gunung Slamet mengalami penurunan dan tergolong terancam punah (endangered). Hal ini dapat disebabkan karena tingkat reproduksi owa jawa yang rendah karena hanya menghasilkan satu anak dalam 3-4 tahun, dan ketersediaan pakan semakin sedikit.

Hasil analisis program DISTANCE 5.0 menunjukkan kepadatan owa jawa di Gunung Slamet dengan luasan $170 \mathrm{~km}^{2}$ adalah 0.26 individu $/ \mathrm{km}^{2}$, koefisien variasi $34.88 \%$, dengan nilai $95 \%$ confidence interval taksiran batas bawah 0.13 hingga 0.52 . Populasi owa jawa di Gunung Slamet mengalami penurunan populasi yang cukup tinggi dibandingkan dengan perkirakan penelitian sebelumnya. Hasil penelitian Setiawan et al. (2012) owa jawa di Gunung Slamet (Curug Gomblang, Pancuran Pitoe, Gunung Malang, Sigugur Semangkung Mlaya) ditemukan 175 individu 
Hasil analisis dilihat pada Histogram data jarak tegak lurus owa jawa terhadap garis transek dan fungsi uniform-hermite polynomial (gambar 1.).

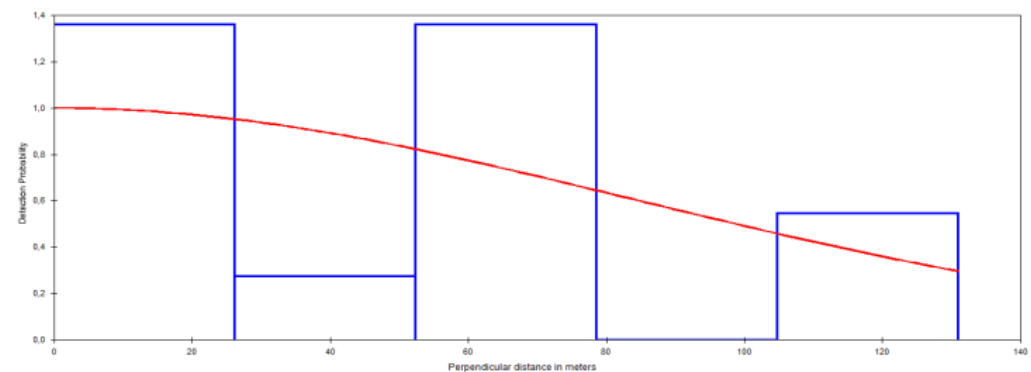

Gambar 1. Histogram data model uniform-hermite polynomial

Semakin dekat jarak peneliti dengan owa jawa maka semakin terlihat jelas dan nilai convidents interval paling kecil maka kepadatan semakin tinggi Populasi owa jawa di Gunung Slamet berstatus endangered karena ukuran populasi hanya 45 individu dengan kepadatan 0,26 individu/km2. Menurut IUCN (1994) menyebutkan jika jumlah populasi suatu taksa kurang dari 250 individu dewasa dan daerah yang ditempati kurang dari $500 \mathrm{~km}^{2}$, maka dapat dikategorikan endangered (terancam punah).

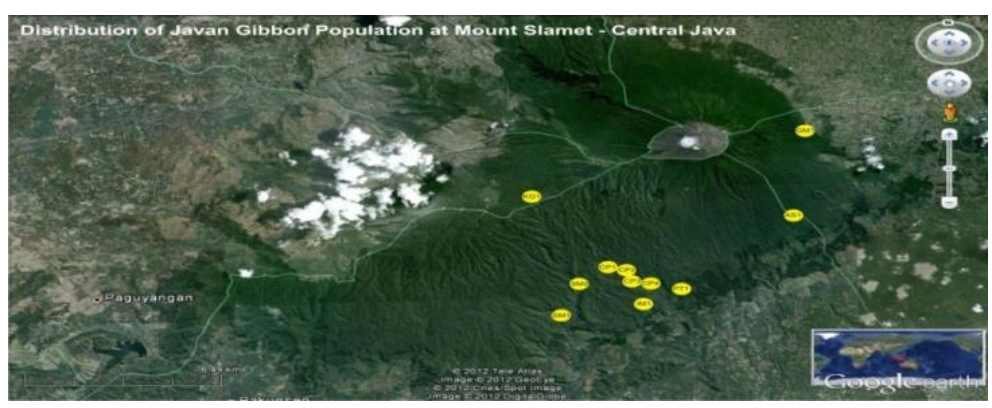

Gambar 2.Peta Distribusi Owa Jawa di Gunung Slamet

2. Jenis tumbuhan yang di jadikan pakan, pohon tidur dan jarak jelajah harian owa jawa

Kepadatan populasi owa jawa dapat berubah-ubah tergantung pada ketersediaan makanan yang berfluktuasi menurut waktu (musim). Pada musim miskin produksi buah owa jawa akan mengunjungi habitat di luar daerah jelajahnya untuk menemukan sumber makanan baru. Luas daerah jelajah tiap kelompok akan meningkat, sehingga luas daerah yang harus di kunjungi bertambah. Owa jawa cenderung menetap di daerah jelajahnya meskipun selama masa paceklik. Perluasan daerah jelajah akan memicu terjadinya konflik antar kelompok, sehingga dapat menyebabkan owa jawa lebih mengintensifkan sumber makanan dengan mengkonsumsi jenis makanan sekunder, antara lain daun, serangga, madu dan telur burung. Pada penelitian ini terdapat 8 jenis tumbuh-tumbuhan yang di jadikan sumber pakan di lokasi penelitian (tabel 2)

Tabel 2 Jenis tumbuhan yang di jadikan pakan di lokasi penelitian

\begin{tabular}{rll}
\hline No & Nama Lokal & Nama Latin \\
\hline 1 & Kebek & Ficus alba \\
2 & Ara & Ficus drupaceae \\
3 & Beringin & Ficus religiosa \\
4 & Bulu & Ficus tingtoria \\
5 & Gongang & Ficus variegate \\
6 & Bulu jerakah & Ficus virens \\
7 & Klengsar & Pometia pinnata \\
8 & Kesambi & Schleichera oleosa \\
\hline
\end{tabular}


Menurut Kappeler (1984), pakan owa jawa berupa buah, daun, kuncup bunga, serangga dan madu. Supriatna \& Wahyono (2000) menyebutkan di Jawa owa jawa mengkonsumsi kurang lebih 125 jenis tumbuhan dari 43 famili. Komposisi pakan terdiri dari buah $61 \%$ dan daun $38 \%$ serta sisanya berbagai jenis makanan seperti bunga dan berbagai serangga. Persentase perbandingan pakan lebih banyak buah dibandingkan daun, maka owa jawa digolongkan ke dalam primata frugivora (Leighton 1987). Iskandar (2007) menyatakan sumber pakan owa jawa adalah vegetasi tingkat pohon seperti Ficus sp dan Rasamala.

Beberapa jenis tumbuhan yang digunakan sebagai pohon tidur owa jawa antara lain pohon Pasang (Lithocarpus sp.) dan Bulu (Ficus sp.). Owa jawa adalah spesies arboreal, tinggal di kanopi hutan bagian atas, serta tidur dan istirahat di bagian pohon dan tajuk tertinggi (emergent trees). Menurut Meijard (2000) kanopi pohon yang cukup tinggi dapat digunakan untuk tempat makan dan tidur, karena kelompok owa jawa memerlukan pohon tertentu yang lebih tinggi sebagai pohon tidur untuk menghindari predator. Menurut Kappeler (1984) jelajah harian owa jawa dapat mencapai $1500 \mathrm{~m}$ dari keseluruhan hutan Gunung Slamet, pergerakan dari satu cabang ke cabang yang lain atau dari pohon ke pohon lain.

\section{Simpulan}

Berdasarkan penelitian dapat disimpulkan bahwa estimasi populasi owa jawa di kawasan penelitian Gunung Slamet terdapat 45 individu yang terdiri 6 anakan, 27 remaja dan 12 dewasa. Owa jawa di Gunung Slamet mengalami penurunan populasi. Jenis tumbuhan yang dijadikan pohon pakan dan tidur diperoleh 8 jenis.

\section{Daftar Pustaka}

Alikodra H.S. 2002. Pengelolaan Satwa Liar Jilid I. Yayasan Penerbit Fakultas Kehutanan IPB.Bogor.

Buckland,S.T.,D.R. Anderson, K.P. Burham and J.L.Lake. (1993) Distance Sampling Estimation Abundance of Biological Population.Chapman \& Hall. London

Chivers, D. J. 1974. The Siamang in Malaja: a Field Study of Primate in Tropical Rain Forest. Plenum Press. New York

Djanubudiman, G., J. Arisona, M. Iqbal, F. Wibisono, G. Mulcahy, M. Indrawan and R. M. Hidayat. 2004. Current Distribution and Conservation Priorities for the Javan Gibbon (Hylobates moloch). Report to
Great Ape Conservation Found, US Fish and Wildlife Service, Washington DC, Indonesian Foundation for Advance of Biological Sciences and Center for Biodiversity and Conservation Studies of University of Indonesia, Depok. 25pp.

Iskandar E. 2007. Habitat dan populasi owajawa (Hylobates moloch Audebert 1797) di Taman Nasional Gunung Halimun Salak JawaBarat.[Disertasi]. Bogor. Sekolah Pascasarjan, Institute PertanianBogor. [Indonesia]

IUCN. 1994. IUCN Red List Categories. Prepared by the IUCN Species Survival Commission.IUCN, Gland, Switzerland.

IUCN/SSC. 2009. The IUCN Red List of the Threstened Species. URL.http://www.iucnredlist.org Diakses 16 April 2013

Kappeler, M. 1984. The Silvery Gibbon (Hylobates lar moloch) Ecology and Behavior. Disertation. Zoologycal Institute of Basel University

Kartono, A. P. Prastyono. Maryanto, I. 2002. Variasi Aktivitas Harian Hylobates moloch (Audebert, 1798) Menurut Kelas Umur di Taman Nasional Gunung Halimun, Jawa Barat.Berita Biologi,6 : 67-73

Leighton, D.R. 1987. Gibbons: Territoriality and Monogamy. In Primate Societies.Editors.B.B. Smuts, D.L.Cheney, R.M. Seyfarth, R.W. Wrangham, and T.T. Struhsaker. University of Chicago Press, Chicago

Meijaard, E., and V. Nijman. 2000. Distribution and conservation of the proboscis monkey (Nasalis larvatus) in Kalimantan, Indonesia. Biological Conservation 92: 1524.

Nijman, V. 2001.Effect of Behaviournal Change due to Habitat Disturbance on Density Estimation in Rain Forest Vertebrate, as Illustrated by Gibbons (Hylobatidae). Pp 217-225 in Hillegers P. J. M. \& de long H. $\mathrm{H}$ (eds) The Balance Between Biodiversity Conservation and Sustainable use of Tropical Rain Forest. Tropenbos, Wangeningen. Netherland

Nijman, V. 2004. Conservation of the Javan Gibbon Hylobates moloch: Population Estimates, Local Extinctions, and Conservation Priorities. The Raffles Bulletin of Zoology, 52(1): 271-280

Setyawan, A.,Tejo Suryo N, Yohannes W.,Vera.I, Sugardjito.J. 2012. Biodiversitas. 13(1): 23-27.

Supriatna, J. dan E. H. Wahyono, 2000. Panduan Lapangan Primata Indonesia.Yayasan Obor Indonesia. Jakarta 
Supriatna, J., J. Manansang, L. Tumbelaka, N. Andayani, U. S. Seal and O. Byers (eds.). 2001. Conservation Assessment and Management Plan for the Primatesof Indonesia. Briefing Book. IUCN/SSC Conservation Breeding Specialist Group (CBSG), Apple Valley, Minnesota. 838pp.

Supriatna, J. 2006. Conservation Programs for the Endangered Javan Gibbon (Hylobates moloch). Conservation International Indonesia, Jakarta, and Departemen of
Biology, University off Indonesia, Depok, Indonesia

Whitmore, TC. 1984. Rropical Rain Forest of The Far East, $2^{\text {nd }}$ ed. Oxford : Clarendon Pres. 